This item was submitted to Loughborough's Research Repository by the author.

Items in Figshare are protected by copyright, with all rights reserved, unless otherwise indicated.

\title{
The design of caring environments and the quality of life of older people
}

PLEASE CITE THE PUBLISHED VERSION

PUBLISHER

(c) Cambridge University Press

LICENCE

CC BY-NC-ND 4.0

REPOSITORY RECORD

Barnes, Sarah. 2019. "The Design of Caring Environments and the Quality of Life of Older People”. figshare. https://hdl.handle.net/2134/2221. 
This item was submitted to Loughborough's Institutional Repository by the author and is made available under the following Creative Commons Licence conditions.

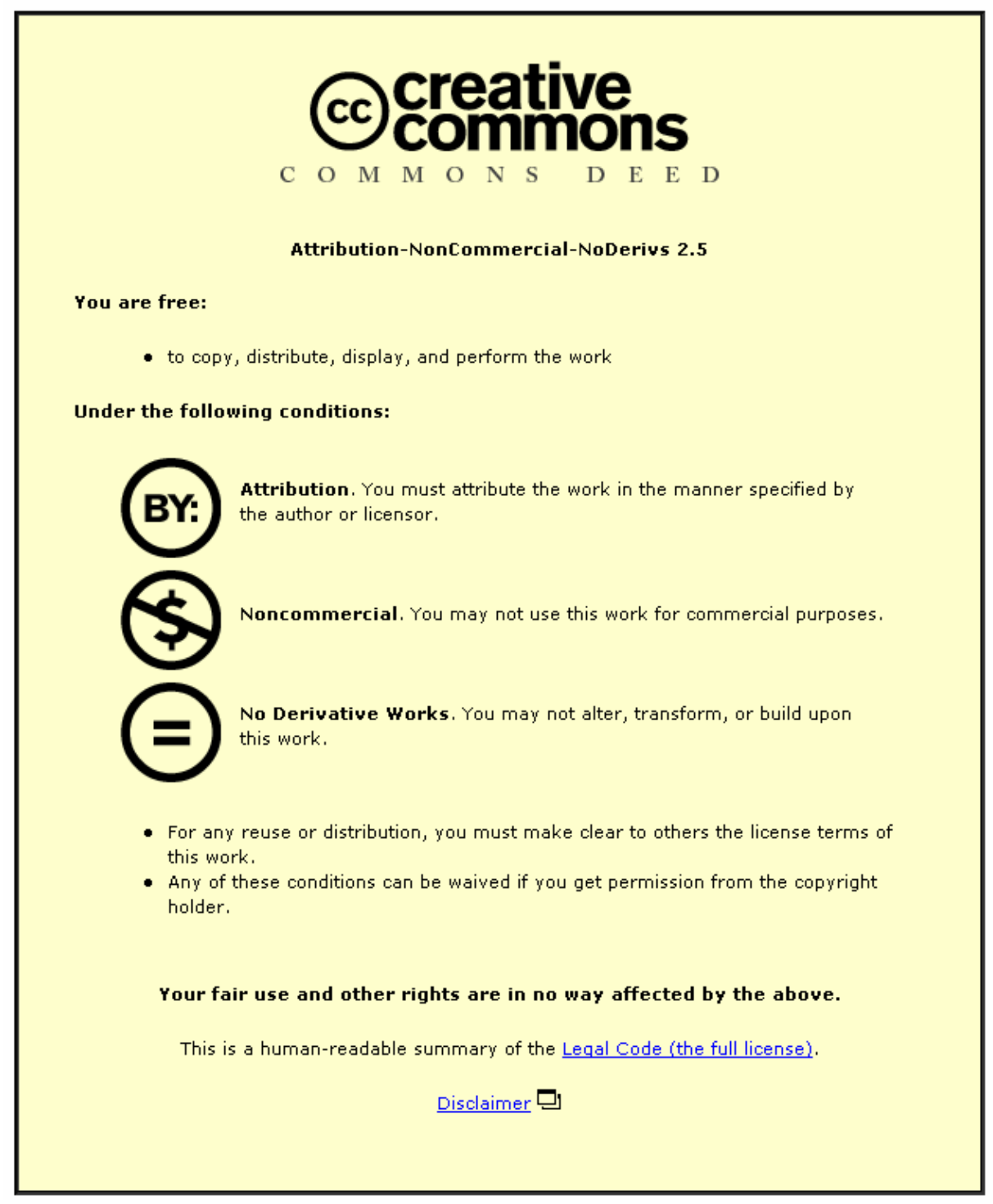

For the full text of this licence, please go to: http://creativecommons.org/licenses/by-nc-nd/2.5/ 
Ageing \& Society 22, 2002, 775-789. (C) 2002 Cambridge University Press

DOI: Io.Ior7/Sor44686Xo20o8899 Printed in the United Kingdom

\title{
The design of caring environments and the quality of life of older people
}

\author{
SARAH BARNES* and the DESIGN IN CARING \\ ENVIRONMENTS STUDY GROUP ${ }^{1}$
}

\begin{abstract}
There has been little systematic research into the design of care environments for older people. This article reviews empirical studies from both the architectural and the psychological literature. It outlines the instruments that are currently available for measuring both the environment and the quality of life of older people, and it summarises the evidence on the layout of buildings, the sensory environment and the privacy of residents. The conclusion is drawn that all evidence-based design must be a compromise or dynamic and, as demands on the caring environment change over time, this compromise must be re-visited in the form of post-occupancy evaluation.
\end{abstract}

KEY WORDS - environment, quality of life, care settings, older people, design.

\section{Introduction}

This article is concerned with the architectural design and physical environment provided by residential and nursing homes for older people, and the impact this has on the quality of life of the residents. To date, there has been little systematic research into such care settings, and this article reviews empirical studies from both architectural and psychological literature in order to investigate key issues in designing caring environments. It outlines the difficulties involved in measuring both the environment and the quality of life of residents, and it emphasises the importance of not only studying the design of buildings, but also the way they are used in practice. The terms 'environment' and 'setting' will be used interchangeably to relate to the care home building and immediate surrounding area that is available to the residents.

* School of Architecture, University of Sheffield. 
In Great Britain, approximately five per cent of people over the age of 65 years live in residential care or nursing homes (Royal Commission on Long Term Care i999). Although a minority of the older

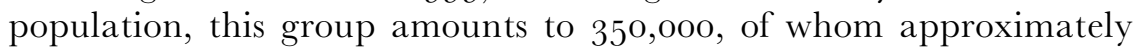
35 ,ooo live in local authority residential homes, I 63, ooo in independent residential homes, and I50,400 in nursing homes (Age Concern 2000). The number of places available in British care homes is however falling because of reduced funding, and this has exacerbated the problems associated with discharging older patients from hospital. The dependency level of older people living in residential homes has been rising. A comparison of long-stay hospitals, residential homes and older people living in the community, carried out between r 979 and r990, found that dependency had risen substantially, particularly in the private sector (Campbell-Stern et al. i 993).

Nursing homes have traditionally followed a medical model and emphasise the provision of skilled nursing care for residents with physical illness rather than cognitive impairment (Williams and Trubatch i 993). Both the research and the professional literature now acknowledge the influence that architecture and design can have on both the well-being of the residents and the quality of care by staff in residential and nursing home settings (Keen i 989; Netten i 993). While their design has rightly emphasised the requirements of the physically frail, it is also recognised that people with cognitive impairment and dementia also have specifiable environmental needs. The architecture and design of care homes for older people must have some influence over the quality of life and care received, but the historical and persistent use of medical models for this type of long-term care clashes with efforts to satisfy the non-medical needs of frail older people (Schwarz 1997). The pattern of provision in the British care home sector is currently changing. Many of the older homes, both purposebuilt and conversions of large private houses, fail to meet the space requirements of the National Minimum Standards, and need extensive refurbishment if they are to continue in use (Department of Health 200I). Ever-larger units are being built to supply different levels of provision within a single building. The former diversity of buildings is tending to narrow, and the basis for evaluating the contribution of different environmental features to quality of life is gradually being lost (Barnes et al. 200 I). 


\section{Measuring the environment}

To date, there has been a shortage of appropriate, comprehensive and objective instruments for assessing the outcomes of building design. This assessment can also be referred to as a post-occupancy evaluation, when a building is revisited in order to establish how it is working in practice. Strategies for assessing nursing or residential home environments tend to be structured using either discrete or global conceptualisations. Discrete or micro-conceptualisations treat the environment as a set of independent variables and typically focus on one or only a few characteristics. On the other hand, global or macro-conceptualisations view the care setting as a single entity, and examine the impact of the whole setting on individuals. There is a shift towards the global or holistic approach which, rather than focusing on discrete behaviours and particular environmental solutions, recognises the more complex set of relationships found in the care setting (Calkins 200 I).

One of the earliest environment assessment instruments is the Multiphasic Environmental Assessment Procedure (MEAP) (Moos and Lemke I996), which was specifically designed to assess both nursing and residential care homes. It includes five separate scales: policy and programme information, resident and staff information, the physical and architectural features, social climate, and a generalised rating scale. The physical and architectural features scale incorporates the domains of community accessibility, physical amenities, social and recreational aids, space availability, safety features, staff facilities, orientational aids and prosthetic aids. The $M E A P$ is however a very detailed assessment (except that it lacks detail in the domain of the sensory environment), and the scoring is biased towards larger, more insitutional care settings, which makes it difficult to use in multi-site studies.

Another such tool, with specific reference to dementia care settings, is the Professional Environmental Assessment Protocol (PEAP) (Lawton et al. 2000). This scale is based on indicators of the attributes of place experience, and it evaluates the extent to which a setting meets each goal. This measure includes eight domains, namely the features that: promote safety and security; promote awareness and orientation; support functional abilities; facilitate social contact; provide privacy; create opportunities for personal control; regulate and promote high quality stimulation; and encourage continuity of the self or individual identity. The team that developed this tool concluded that the minimum environmental assessment should include items evaluating residents' awareness and orientation, environmental stimulation and challenge, safety and security, privacy and control, healthy and 
familiar environment, and general comfort (Teresi et al. 2000). It should be noted that the PEAP requires administration by an expert in environmental design.

Other environment assessment instruments have been devised for the specific purpose of assessing Special Care Units, which are designed for people with dementia and were established in the United States and Canada during the early ig9os. They are separate units of approximately 20 beds with specially trained staff and programmes that are housed in a much larger nursing home (Grant and Sommers i 998). Assessment instruments for these settings include the Therapeutic Environment Screening Scale (TESS) (Sloane et al. 2002), which has 84 discrete items and one global scale covering i 3 conceptual domains. This descriptive instrument was originally developed to differentiate between the environments of Special Care Units and traditional nursing homes. The Environment-Behaviour $(E-B)$ model (Zeizel et al. I 994) includes both descriptive and evaluative assessments of Special Care Units, and it combines aspects of both global and discrete perspectives. Like the $M E A P$, both of these assessment instruments are based on United States care settings which tend to be much larger than the British equivalents.

\section{Measuring the quality of life}

Defining quality of life for older people is highly problematic. There is a tension between the need for objective standards and an imperative to take into account the subjective nature of the quality of life. Therefore, any definition and attempt at measurement should include both objective and subjective indicators and should include all facets, not only the good things in a person's life, but also the bad things (Farquhar i 995). A consensus has developed in the conceptualisation of quality of life as a multidimensional construct, containing domains of physical health, psychological wellbeing, social relationships and the physical environment (World Health Organisation Quality of Life (WHOQoL) Group I 998).

In the past, there has been a problem of measuring this complex construct, particularly in the residential care population where levels of cognitive impairment are high. Nevertheless, some progress has been made in assessment, utilising instruments that elicit a subjective evaluation of quality of life amongst this population. The Subjective Evaluation of Individual Quality of Life $(S E I Q O L)$ procedure determines which domains of the quality of life are meaningful to the individual 
(Coen et al. i 993). It uses a structured interview technique followed by manipulation of a moveable 'pie chart' to demonstrate the importance of each of the domains. Other research has suggested that the observable behaviours of people with dementia can offer insights into their internal states, leading to more emphasis being placed on understanding their subjective world (Lawton 200I; Russell i996; Kitwood and Bredin I992). Kitwood and Bredin (I992) describe an observational method for evaluating the process of dementia care, known as Dementia Care Mapping (DCM). They have developed this into an important research tool, the 'DCM Method' (I 992), which enables a detailed and structured appraisal of the care given to people with dementia in 'formal' settings. DCM gives priority to the capabilities and needs of each individual. A further method of measurement is proxy assessment carried out by a close relative or key worker of the individual concerned (Albert et al. I 996). Quality of life in dementing illness comprises the same areas as in people in general, and the most successful way of assessing this is by using a combination of quality of life indicators (Lawton i 994). A comprehensive review of measures of the quality of life in older people is beyond the scope of this review (readers can refer to Bowling i997).

\section{Existing evidence for design in caring environments}

There is an overall shortage of empirical evidence on the physical environment in care settings, for most studies have been small scale or anecdotal. This should be borne in mind when considering the design guidelines presented below. The main areas which have been investigated involve the general layout of the building, the sensory environment within the building, and the privacy and autonomy of the residents. These are discussed in more detail below.

\section{Layout, wayfinding and special environments}

Disorientation in residents, caused by dementia and the immediate effect of institutionalisation, is an increasing problem for the architects who design residential and nursing homes. There is little information on ways of designing buildings which are reassuring and comprehensible to a person suffering from dementia, but the emphasis should be on small, local and domestic settings (Marshall i 992). In terms of the size of residential homes, overall satisfaction with the scale of residential life is depressed when home size exceeds 50 beds, which 
leads to more complex designs and fewer opportunities to talk to staff (Kellaher i 986). The group-living design was initially thought to offer a more homelike environment, with residents living in small independent groups of about io, with separate facilities. The configuration has no equivalent in non-institutional society, being neither wholly medical, nor institutional nor domestic, though all these are present in some degree (Kellaher i 986).

Wayfinding refers to the problem-solving abilities necessary to reach destinations. Nursing and residential homes which facilitate spatial orientation and wayfinding can contribute to a person's quality of life but there are few empirical studies (Passini et al. 2000). One study examined the effect of design on the ability of residents with dementia to find their way around in a few residential homes. Using a newlydevised, unauthenticated measure of wayfinding, it was concluded that homes where the residents lived in groups provided a more favourable design, and that the level of lighting was important in finding their way around. Residents living in care homes which had been adapted from older premises were more able to find their way around than those in new premises. 'Meaningful decision points', such as notable architectural features, facilitate a resident's wayfinding ability in both types of home (Netten r 989). Passini et al. (1998) explored wayfinding abilities in people with Alzheimer's disease. They carried out a qualitative study using a small sample of patients with a dementia diagnosis and a control group. Their results showed that most participants were incapable of developing an overall plan to solve the wayfinding task, or of making decisions involving memory or inference. They were, however, more able to make decisions in buildings with well-articulated entrances, staircases and landmarks. Kidd (1996) points out that observing people move around in buildings is a useful method of assessing wayfinding skills. He suggests some design criteria which translate into two major approaches, the 'introverted' and the 'extroverted plan form'. The introverted plan has the main activities area in the centre of the building and there is restricted access to the outside: the key design feature is total visual access. The extroverted plan is based on a conventional house plan, enclosed by acceptable fencing: the key feature is the familiarity of the house design.

'Reality orientation' is a technique that started in r 950s America and provides a framework in which staff are encouraged to see residents as people rather than a collection of tasks (Kitwood I997). It is specifically designed for residents who are confused and involves structuring the care setting with signs and cues to help the resident to remain aware of their surroundings. The technique, however, lacks a sound knowledge 
base and is difficult to evaluate (Holden and Woods ig82). Some studies have found that residents find the reality-orientation cues patronising and child-like (Voelkel r978; MacDonald and Settin I978).

The United States 'Special Care Units' are well-adapted living environments, which not only meet the basic requirements for lighting, heating and acoustics, but also support the special behavioural needs of people with dementia in the more advanced stages (Grant and Sommers i 998). Various research projects have been carried out in the Special Care Units, and they recommend that for residents to have maximum autonomy, independence and privacy, the units should be small and have specially-trained staff. Residents with mild or moderate dementia should be housed in ground floor facilities with easy access to outdoor spaces, which provide paths for wandering as well as visual and other sensory stimulation (Williams and Trubatch i 993; Swane I 992 ).

Manser ( I 989) has also addressed the needs of people with dementia from an architectural perspective, reasoning that they retain the capacity to respond to shape, size and light and also an instinct for privacy and modesty. He stresses the importance, when designing for this population, of maintaining simple ideas, including symmetry, balance and the avoidance of corridors. He suggests that a welldesigned, well-proportioned building with generous windows and high levels of daylight will not only improve the quality of life of the residents, but also improve the morale of their carers and therefore the quality of their care. If staff have more adequate physical facilities, it has been found that they are more likely to establish clear policies and provide residents with more choice in their daily activities (Moos and Schaefer i 987). More detailed aspects of designing for people with dementia include the sensory environment, interior design and the role and function of appropriate seating (Brawley i 997; Peachment I 996).

\section{Sensory environments}

Sensory stimulation is concerned with the different elements of sight, smell, hearing and touch. Attention to these qualities is an important aspect of the caring environment, as the confusion suffered by people with dementia is caused in part by reduced sensory receipts through the reticular activating system of the brain (Marieb i 995). Multi-sensory environments provide sensory stimulation and often involve special rooms, referred to as 'snoezelens', which have been created to present various sensory stimulants. They may have positive benefits, such as 
inducing greater happiness and calmness and a reduction in sadness and fear (Moffat et al. i993). Studies of these sensory rooms or snoezelens warn that improvements in the users' quality of life may result from increased staffing rather than the environment itself (Woodrow i 998).

A garden is an important part of the care setting and can provide diverse sensory stimulation, including sound, colour and fragrance. Outside spaces are often added to care homes as decorative features but without thought being given to their therapeutic benefits. Wellconceived external environments can provide older people with spaces for privacy, activity and stimulation, all of which can contribute to an improved quality of life (Brawley 200 I). Enriching the care home environment is thought to enhance the well-being of its residents. Using visual, auditory and olfactory stimuli, Cohen-Mansfield and Werner ( I998) attempted to simulate two care environments, the home and the outdoors. They found that residents appeared to prefer the enhanced environments which provide a low-cost method of improving the surroundings, although the effect was not large, the sample was small and the period of intervention short.

A substantial amount of research points to the significance of both artificial and natural light on various behaviours in the nursing and residential home environment although with inconsistent emphases and results (Okumoto et al. I 998; Kolanowski i 990). There are positive and negative aspects of sunlight in indoor space. The negative factors include glare and overheating, while positive factors include using it as a source of heating, or to enhance the visual and emotional wellbeing of the occupants. In environments where the well-being of the occupant is an important concern to the designer, this intrusion of sunlight ought to be controlled (Boubekri et al. I99I). In an experimental study of improved lighting in a reading area, follow-up interviews over three years indicated a relationship between the lighting and an improved quality of life of older people (Sorensen and Brunnstron i 995). The participants did not want to return to the previous poor lighting conditions.

Privacy, space and autonomy

Research findings suggest that privacy is a most important aspect of the environment of older people (Morgan and Stewart i998; Duffy et al I 996). Keen ( I 989) describes three dimensions of privacy in relation to the physical environment: visual, acoustic and olfactory. Netten ( I993), on the other hand, describes privacy in terms of the social 
environment, and defines it as the need to be separate from others or the degree to which one is separate from the community. Personal space is the area immediately surrounding an individual, and if the individual has control over that space it becomes claimed territory or 'defensible space'. Space which is not defensible undermines the sense of ownership residents may attach to their rooms, while restrictions on the use of the space or frequent uninvited intrusions by staff can undermine a sense of ownership of the personal territory. A study of one Special Care Unit suggests that personal variables, such as cognitive impairment, affect and perceptual changes associated with dementia, could interact with environmental variables, such as density and privacy, and negatively influence the behaviour of the resident (Morgan and Stewart i998). Duffy et al.'s (ig86) action research project on two nursing homes found that, although both administrators and designers favoured designs that promoted social interaction, nursing home residents consistently selected designs that enhanced privacy. This clearly highlights the need for users to be involved in the design process. The authors suggest that if better privacy options were included in the design of care homes, social interaction may be more welcome.

The boundary which distinguishes home from the outside world is one of the physical markers of privacy, but within this boundary other markers operate which reinforce and allow more subtle gradations of privacy. A more 'homelike' gradation of space may provide small private places for receiving visitors other than the resident's own bedroom, for example a conservatory or small, quiet lounge. Residents should have the opportunity to choose from several spaces where they may want to spend time, and this opportunity for choice may help to reduce the sense of intrusion into personal space (Brawley i 997). A small qualitative study carried out by Morgan and Stewart (I999) found that relatives and staff felt that many residents enjoyed having their own private space. However, they believed that the unit should also have several semi-private rooms so that residents who were positive about having a room-mate would also have the option of privacy; for double rooms provide few opportunities for controlling social interaction. The authors suggest that an ideal environment would provide opportunities for both privacy and interaction.

Within the privacy of their own home, a person can control and conceal their declining capacities in the management of daily living. On the other hand, a care home is arranged physically and organisationally to be a communal arena, so the control and concealment of frailty permitted at home are no longer possible. Frailty 
can be revealed and exposed and personal power diminished (Willcocks et al. I 987). The determinants of enhanced or maintained quality of life may broadly be summed up as those factors which permit residents to control and organise their lives in care (Kellaher i986). Evidence suggests that residents are more satisfied with and express definite preferences for those care arrangements which offer a fundamental rather than token measure of control over their freedom of choice. An inability to control the residential environment, for whatever reason, appears to be associated with reduced satisfaction. This can include having no control of heating and ventilation in the resident's bedroom. When bedrooms are defensible and private, residents are more likely to personalise their rooms, which indicates that they feel a greater sense of territory. This sense of ownership, privacy and control over the environment enhances the quality of life (Willcocks et al. I987).

The balance between autonomy and security characterises the search for an ideal architectural setting able to keep both support and stimulation in equal focus (Parmalee and Lawton i990). The physical attributes of the architectural framework are not important in themselves, only in that they can provide a degree of autonomy and individual choice for residents. Ideally, plans should take into account residents' characteristics, staff attributes, intended programme and the physical features of the environment, all of which are important (Schwarz and Brent i 999; Cohen-Mansfield et al. 1995).

\section{Priorities for future research and design}

Research to date has provided only a broad understanding of the complexities of care settings and their influence on both residents and staff. For example, the majority of evidence falls into the categories of overall building layout, the sensory environment and the provision of semi-private spaces. Most of the evidence is anecdotal and does not substantiate statements about 'best buildings', and most refers primarily to traditional residential and nursing home settings. While these currently provide the majority of care homes in Britain, they may have a limited capacity to respond to the changing needs of residents. A new generation of buildings is emerging in response to the aim of enabling people to live independently, in the form of more flexible, supportive housing schemes. These schemes offer various levels of support, with the intention of providing flexible care that can increase with the older person's needs (Peace and Holland 200I). There is a need, however, to evaluate the extent to which these schemes genuinely 
facilitate flexible care. Empirical studies are needed in order to gather the views of all parties concerned, including residents, visitors, staff and care home managers (Abbey and Schneider i 999).

While appropriate comprehensive and objective instruments for assessing the design of care home buildings remain underdeveloped, some progress has been made. However, most of the instruments have been developed in north America where the emphasis is on much larger care homes containing separate Special Care Units for residents with dementia. There is still a need for validated and reliable instruments, more relevant to British care settings, which can be used to assess buildings both 'as designed' and 'in use'. A framework is also needed for articulating the difference between person-centred issues like privacy, autonomy and choice, and the physical needs of the residents. Many different indicators of quality of life have been developed, and research indicates that using a combination of these, for example, proxy questionnaires, observations and interviews, may prove the most successful in assessing the quality of life of older people in residential care settings (McKee et al. i998).

The ways in which a building meets the needs of the residents is of importance not only when it is being designed, it should also be regularly reviewed after it is occupied in the form of a 'post-occupancy evaluation'. Buildings are expensive and last a long time and it can be difficult, if not impossible, to retrofit a care home in order to meet new miminum standards, particularly when there are dimensional constraints. This can result in users having to compromise or, in extreme cases, buildings being demolished or changing in function because they are unable to be adapted to meet minimum standards. This cost of building renewal can mean a reduction in resources available for care.

A close liaison between health care professionals and designers, alongside input from evidence-based research, could help to influence the quality of the buildings being designed. There is a need for dialogue among all concerned, for a multi-disciplinary approach to design, and for more emphasis on post-occupancy evaluation, with quality of life as one of the criteria of the success of the design. It seems that, as yet, 'researchers are uncomfortable with designers' inability to predict the performance of their buildings in relation to human activity' (Schwarz and Brent I 999: xxv).

\section{Acknowledgements}

Funding for the project was provided by the Engineering and Physical Sciences Research Council (GR/M70025). 


\section{NOTE}

I The article has been written on behalf of the 'Design in Caring Environments Study Group': Kevin J. McKee and Christine J. Parker (Sheffield Institute for Studies on Ageing, University of Sheffield, UK), Kevin Morgan (Department of Human Sciences, University of Loughborough, UK), and Judith M. Torrington and Peter R. Tregenza (School of Architecture, University of Sheffield).

\section{References}

Abbey, A., Schneider, J. and Mozley, C. I 999. Visitors' views on residential homes. British Journal of Social Work, 29, 4, 567-79.

Age Concern England 200o. Giving You Practical Help, Information and Advice ... to Get More from Life. Available online at: http://www.ageconcern.co.uk/.

Albert, S. M., Del Castillo-Casteneda, C., Sano, M., Jacobs, D. M., Marder, K., Bell, K., Bylsma, F., Lafleche, G., Brandt, J., Albert, M. and Stern, Y. I996. Quality of life in patients with Alzheimer's disease as reported by patient proxies. Fournal of the American Geriatrics Society, 44, I $342^{-2} 7$.

Barnes, S., McKee, K. J., Morgan, K., Parker, C. J., Torrington, J. M. and Tregenza, P. R. 200 I. The design in caring environments study. In Tester, S., Archibald, C., Rowlings, C. and Turner, S. (eds), Quality in Later Life: Rights, Rhetoric and Reality. Proceedings of the British Society of Gerontology zoth Annual Conference, Stirling 200 I. University of Stirling, I $72-7$.

Boubekri, M., Hulliv, R. B. and Boyer, L. L. I99 I. Impact of window size and sunlight penetration on office workers' mood and satisfaction. Environment and Behaviour, 23, 474-93.

Bowling, A. I997. Measuring Health: A Review of Quality of Life Measurement Scales, 2nd Edition. Open University Press, Buckingham.

Brawley, E. C. г997. Designing for Alzheimer's Disease: Strategies for Creating Better Care Environments. John Wiley and Sons, New York.

Brawley, E. C. 200 I. Environmental design for Alzheimer's disease: a quality of life issue. Aging and Mental Health, 5, Supplement I, S79-83.

Calkins, M. P. 200I. The physical and social environment of the person with Alzheimer's disease. Aging and Mental Health, 5, Supplement 2, $\mathrm{S}_{74-78 .}$

Campbell Stern, M., Jagger, C., Clarke, M., Anderson, J., McGrother, C., Battock, T. and McDonald, C. I993. Residential care for elderly people: a decade of change. British Medical fournal, 306, 827-30.

Coen, R., O’Mahony, D., O’Boyle, C., Joyce, C. R. B., Hiltbrunner, B., Walsh, J. B. and Coakley, D. I993. Measuring the quality of life of dementia patients using the Schedule for the Evaluation of Individual Quality of Life. Irish Fournal of Psychology, I4, I 54-63.

Cohen-Mansfield, J., Werner, P., Weinfield, M., Braun, J., Kraft, G., Gerber, B. and Willens, S. 1995. Autonomy for nursing home residents: the role of regulations. Behavioral Sciences and the Law, I3, 4I $5^{-23}$.

Cohen-Mansfield, J. and Werner, P. I998. The effects of an enhanced environment on nursing home residents who pace. The Gerontologist, 38, 2, I 99-208.

Department of Health 200 I. Care Homes for Older People: National Minimum Standards. Stationery Office, London.

Duffy, M., Bailey, S., Beck, B. and Barker, D. G. i 996. Preferences in nursing home design: a comparison of residents, administrators and designers. Environment and Behaviour, 18, 2, 246-57. 
Farquhar, M. i995. Elderly people's definitions of quality of life. Social Science and Medicine, 4I, I 439-46.

Grant, L. A. and Sommers, A. R. I998. Adapting living environments for persons with Alzheimer's disease. Geriatrics, 53, Supplement I, S6 I-65.

Holden, U. P. and Woods, R. T. I982. Reality Orientation: Psychological Approaches to the 'Confused' Elderly. Churchill Livingstone, Edinburgh.

Keen, J. I989. Interiors: architecture in the lives of people with dementia. International Journal of Geriatric Psychiatry, 4, 255-72.

Kellaher, L. A. I986. Determinants of quality of life in residential settings for old people. In Judge, K. and Sinclair, I. (eds), Residential Care for Elderly People. Her Majesty's Stationery Office, London.

Kidd, B. J. i996. 'A journey with Alice'. In Marshall, M. (ed.), State of the Art in Dementia Care. Centre for Policy on Ageing, London.

Kitwood, T. i997. Dementia Reconsidered. Open University Press, Buckingham.

Kitwood, T. and Bredin, K. I 992. A new approach to the evaluation of dementia care. Fournal of Advances in Health and Nursing Care, $\mathbf{I}, 4 \mathrm{I}-60$.

Kolanowski, A. M. I990. Restlessness in the elderly: the effect of artificial lighting. Nursing Research, 39, 3, I8 I-3.

Lawton, M. P. i994. Quality of life in Alzheimer's disease. Alzheimer's Disease and Associated Disorders, 8, 3, I38-50.

Lawton, M. P., Weisman, G., Sloane, P., Norris-Baker, C., Calkins, M. and Zimmerman, Z. I. 2000. A 'Professional Environmental Assessment Procedure' for special care units for elders with dementing illness and its relationship to the 'Therapeutic Environment Screening Schedule'. Alzheimer Disease and Associated Disorders, 14, 28-38.

Lawton, M. P. 200 I. The physical environment of the person with Alzheimer's disease. Aging and Mental Health, 5, Supplement I, $\mathrm{S}_{5} 6-64$.

Macdonald, M. L. and Setting, J. M. i 978 . Reality orientation versus sheltered workshops as treatment for the institutionalized ageing. Fournal of Gerontology, 33, 4I6-2 I.

Manser, M. I989. The architecture of institutions for demented persons. In Wertheimer, J., Baumann, P., Gaillard, M. and Schwed, P. (eds), Innovative Trends in Psychogeriatrics. Karger, Basle, 22-7.

Marieb, E. N. I995. Human Anatomy and Physiology, 3rd Edition. Benjamin/Cummings, Redwood City, California.

Marshall, M. i 992. Designing for disorientation. Access by Design, 58, I 5-7.

McKee, K. J. and Barnes, S. 1998. An analysis of different methods for assessing quality of life in older people. International Fournal of Psychology, 35, 3-4, I 22.

Moffat, N., Barker, P. and Pinkney, L. i993. Snoezelen: An Experience for People with Dementia. Rompa, Chesterfield, Derbyshire.

Moos, R. H. and Schaefer, J. A. I 987 . Evaluating health care work settings: a holistic conceptual framework. Psychology and Health, I, 97-122.

Moos, R. H. and Lemke, S. r 996. Evaluating Residential Facilities. Sage, London.

Morgan, D. G. and Stewart, N. J. i 998. Multiple occupancy versus private rooms on dementia care units. Environment and Behaviour, 3o, 4, 487-503.

Morgan, D. G. and Stewart, N. J. i 999. The physical environment of Special Care Units: needs of residents with dementia from the perspective of staff and family caregivers. Qualitative Health Research, 9, I, I05-18.

Netten, A. I989. The effect of design of residential homes in creating dependency among confused elderly residents : a study of the elderly demented residents and their ability to find their way around homes for the elderly. International Fournal of Geriatric Psychiatry, 4, I 43-53. 
Netten, A. 1993. A Positive Environment? Physical and Social Influences on People with Senile Dementia in Residential Care. Ashgate, Aldershot, Hampshire.

Okumoto, Y., Koyama, E., Matsubara, H., Nakano, T. and Nakamura, R. I 998. Sleep improvement by light in a demented aged individual. Psychiatry and Clinical Neuroscience, 52, 2, 194-6.

Parmalee, P. and Lawton, M. P. I990. The design of special environments for the aged. In Birren, J. and Schaie, K. (eds), Handbook of the Psychology of Aging, 3rd Edition. Academic, New York.

Passini, R., Rainville, C., Marchand, N. and Joanette, Y. I998. Wayfinding and dementia: some research findings and a new look at design. Fournal of Architectural Planning and Research, 15, 2, 133-51.

Passini, R., Pigot, H., Rainville, C. and Tetreault, M.-H. 20oo. Wayfinding in a nursing home for advanced dementia of the Alzheimer's type. Environment and Behavior, 32, 5, 684-7 I 0.

Peace, S. M. and Holland, C. (eds) 200 r. Inclusive Housing in an Ageing Society. Policy Press, Bristol.

Peachment, G. I996. 'You're sitting in my chair': an enquiry into the role and function of appropriate seating for the active person with dementia. In Marshall, M. (ed.), State of the Art in Dementia Care. Centre for Policy on Ageing, London.

Royal Commission on Long Term Care 1999. With Respect to Old Age: Long Term Care-Rights and Responsibilities. Stationery Office, London.

Russell, C. K. I996. Passion and heretics: meaning in life and quality of life of persons with dementia. Fournal of the American Geriatrics Society, 44, I400-2.

Schwarz, B. I997. Nursing home design: a misguided architectural model. Fournal of Architectural Planning and Research, I4, 4, 343-59.

Schwarz, B. and Brent, R. (eds) i999. Aging, Autonomy and Architecture: Advances in Assisted-Living. Johns Hopkins University Press, Baltimore.

Sloane, P. D., Mitchell, C. M., Weisman, G., Zimmerman, S., Long Foley, K. M., Lynn, M., Calkins, M., Lawton, M. P., Teresi, J., Grant, L., Lindeman, D. and Montgomery, R. 2002. The Therapeutic Environment Screening Survey for Nursing Homes (TESS-NH): an observational instrument for assessing the physical environment of institutional settings for persons with dementia. Fournal of Gerontology, $57 \mathbf{B}, 2, \mathrm{~S} 69-78$.

Sorensen, S. and Brunnstrom, G. i995. Quality of light and quality of life: an intervention study among older people. Lighting Research and Technology, 27, 2, I I 3-8.

Swane, C. E. I 992. Improving environment and care for elderly people with dementia. Danish Medical Bulletin, 39, 3, 253-5.

Teresi, J. A., Holmes, D. and Ory, M. G. 200o. The therapeutic design of environments for people with dementia: further reflections and recent findings from the National Institute on Aging Collaborative Studies of Dementia Special Care Units. The Gerontologist, 40, 4, 4I 7-2 I.

Voelkel, D. I978. A study of reality orientation and resocialisation groups with confused elderly. Fournal of Gerontological Nursing, 4, 3-18.

WHOQoL Group i998. The World Health Organisation Quality of Life Assessment (WHOQoL): development and general psychometric properties. Social Science and Medicine, 46, I 2, I 569-85.

Willcocks, D., Peace, S. and Kellaher, L. I987. Private Lives in Public Places: A ResearchBased Critique of Residential Life in Local Authority Old People's Homes. Tavistock, London.

Williams, J. K. and Trubatch, A. D. i 993. Nursing home care for the patient with Alzheimer's disease: an overview. Neurology, 43, Supplement 4, S2O-24.

Woodrow, P. ig98. Interventions for confusion and dementia 4: alternative approaches. British Fournal of Nursing, 7, 20, I 247-50. 
Caring environments and older people's quality of life 789

Zeizel, J., Hyde, J. and Levkoff, S. i 994. Best practices: an environment-behavior model for Alzheimer special care units. American Fournal of Alzheimer's Care and Related Disorders and Research, 9, 4-2 I.

Accepted I8 May 2002

Address for correspondence:

Sarah Barnes, School of Architecture, Arts Tower, Western

Bank, University of Sheffield, Sheffield Sio 2TN, UK.

e-mail:s.barnes@sheffield.ac.uk 